\title{
Ketamine-Induced NMDA Receptor Hypofunction as a Model of Memory Impairment and Psychosis
}

\author{
John W. Newcomer, M.D., Nuri B. Farber, M.D., Vesna Jevtovic-Todorovic, M.D., Ph.D., \\ Gregg Selke, B.A., Angela Kelly Melson, M.A., Tamara Hershey, Ph.D., Suzanne Craft, Ph.D., \\ and John W. Olney, M.D.
}

$N$-methyl-D-aspartate (NMDA) glutamate receptor antagonists are reported to induce schizophrenia-like symptoms in humans, including cognitive impairments. Shortcomings of most previous investigations include failure to maintain steady-state infusion conditions, test multiple doses and/or measure antagonist plasma concentrations. This double-blind, placebo-controlled, randomized, within-subjects comparison of three fixed subanesthetic, steady-state doses of intravenous ketamine in healthy males $(n=15)$ demonstrated dose-dependent increases in Brief Psychiatric Rating Scale positive $(F[3,42]=21.84 ; p<0.0001)$ and negative symptoms $(F[3,42]=2.89 ; p=0.047)$, and Scale for the Assessment of Negative Symptoms (SANS) total scores $(F[3,42]=$ 10.55; $p<0.0001$ ). Ketamine also produced a robust dosedependent decrease in verbal declarative memory performance $(F[3,41]=5.11 ; p=0.004)$, and preliminary evidence for a similar dose-dependent decrease in nonverbal declarative memory, occurring at or below plasma concentrations producing other symptoms. Increasing NMDA receptor hypofunction is associated with early occurring memory impairments followed by other schizophrenia-like symptoms.

[Neuropsychopharmacology 20:106-118, 1999] (C) 1998 American College of Neuropsychopharmacology Published by Elsevier Science Inc.
KEY WORDS: NMDA; Ketamine; Schizophrenia; Memory; Glutamate; Cognition

Considerable research interest has recently been focused on the role of glutamate and related neural circuitry in

From the Department of Psychiatry (JWN, NBF, GS, AKM, TH, JWO), Department of Anesthesiology (VJ-T), and Department of Pathology (JWO), Washington University School of Medicine, St. Louis, Missouri; the Department of Psychology (JWN), Washington University, St. Louis, Missouri; the Department of Psychiatry (SC), and Department of Behavioral Science (SC), University of Washington, Seattle, Washington; and Department of Geriatric Research (SC), Education \& Clinical Center, Seattle/American Lake VAMC, Seattle, Washington.

Address correspondence to: John W. Newcomer, M.D., Department of Psychiatry, Washington University School of Medicine, 4940 Children's Place, St. Louis, MO 63110.

Received March 18, 1998; revised June 19, 1998; accepted June 29, 1998. the neurobiology of schizophrenia. The results of these investigations have emphasized hypofunction of glutamatergic neurons and/or the N-methyl-D-aspartate (NMDA) glutamate receptor (Tsai et al. 1995; Kim et al. 1980a, 1980b; Sherman et al. 1991; Deutsch et al. 1989; Javitt and Zukin 1991; Olney 1988a; Olney 1988b; Olney and Farber 1995). An important element of several of these theoretical positions is that NMDA receptor hypofunction (NRH) produced by any mechanism can be psychotogenic. This has renewed interest in the clinical effects of NMDA glutamate receptor antagonists.

Ketamine and phencyclidine (PCP) are non-competitive NMDA glutamate receptor antagonists (Zukin and Zukin 1979; Vincent et al. 1979; Lodge and Anis 1982; Lodge et al. 1987) which can produce a transient state of $\mathrm{NRH}$ in the brain. Early investigators characterized a PCP-induced clinical syndrome of schizophrenia-like 
symptoms, including hallucinations, delusions, idiosyncratic and illogical thinking, poverty of speech and thought, agitation, disturbances of emotion, affect, withdrawal, decreased motivation, and dissociation (Johnstone et al. 1959; Luby et al. 1959; Rosenbaum et al. 1959; Luby et al. 1962; Corssen and Domino 1966; Bakker and Amini 1961; Davies and Beech 1960; Domino and Luby 1981). This PCP-induced syndrome can be indistinguishable from acute presentations of schizophrenia (Yesavage and Freeman 1978; Erard et al. 1980). Ketamine, a PCP analog still used in human anesthesia, has been reported to cause reactions similar to but not as severe as those caused by $\mathrm{PCP}$, including brief, reversible "positive" and "negative" schizophrenia-like symptoms (Krystal et al. 1994; Malhotra et al. 1996). Both PCP and ketamine can exacerbate psychosis in schizophrenia (Luby et al. 1959; Luby et al. 1962; Lahti et al. 1995a; Lahti et al. 1995b; Malhotra et al. 1997).

Declarative, explicit or secondary memory and learning deficits in patients with schizophrenia occur early in the course of the illness and are quantitatively large compared with deficits in other differentiated elements of cognitive performance, showing stability "on" versus "off" antipsychotic medication and over repeated testing (Gruzelier et al. 1988; Saykin et al. 1991, 1994; Cannon et al. 1994). Clinical and preclinical investigations suggest the hypothesis that changes in NMDA glutamate receptor activity in patients with schizophrenia may be causally related to memory impairments found in this disorder. Relevant to this hypothesis, the activation of post-synaptic NMDA receptors is important for the induction of the activity-dependent synaptic modification called long-term potentiation (LTP) (Bliss and Collingridge 1993; Collingridge and Bliss 1995), and hippocampal LTP has been postulated to underlie certain memory functions (Doyere and Laroche 1992; Sakimura et al. 1995; Davis et al. 1992). In animals, both competitive and non-competitive NMDA antagonists can impair performance on spatial (Handelman et al. 1987; Balster and Chait 1976; McLamb et al. 1990; Mondadori et al. 1989; Morris et al. 1986; Morris 1989; Morris et al. 1990; Danysz et al. 1988; Ward et al. 1990; Butelman 1989; Spangler et al. 1991) and nonspatial (Tonkiss et al. 1988; Crooks et al. 1989; Jones et al. 1990; Parada-Turska and Turski 1990; Pontecorvo et al. 1991) memory tasks which are also affected by hippocampal lesions. Similar impairments in learning and memory (e.g., delayed matching-to-sample) have been reported in nonhuman primates (Thompson et al. 1987; Thompson and Moerschbaecher 1984; Buffalo et al. 1994; Frederick et al. 1995). In rodents and nonhuman primates, the induced memory defect appears to involve acquisition or encoding of information (Walker and Gold 1991; Spangler et al. 1991; McNamara and Skelton 1993; Buffalo et al. 1994). Acute PCP effects in humans include reductions in memory performance, psychomotor processing speed, selective attention, and reaction time (Rosenbaum et al. 1959; Davies and Beech 1960; Bakker and Amini 1961; Cohen et al. 1962). Ketamine anesthesia is associated with transient anterograde amnesia (Pandit et al. 1971), and subanesthetic doses of ketamine in healthy humans have been reported to produce acute decreases in memory performance, not accounted for by attentional deficits, as well as decreases in sustained attentional performance, verbal fluency, and Wisconsin Card Sort performance (Harris et al. 1975; Ghoneim et al. 1985; Krystal et al. 1994; Malhotra et al. 1996).

Unfortunately, most previous investigations of ketamine effects on mental symptoms and cognitive function in humans have been limited by a lack of a steadystate infusion conditions, limited numbers of dose levels, and/or failure to measure plasma ketamine and metabolite levels. Some intravenous (IV) ketamine infusion studies, for example, allowed plasma ketamine levels to rise over the experimental assessment conditions, prohibiting conclusions about the relationship between specific plasma levels and various features of the behavioral response. This experiment aimed to identify a subanesthetic dose of the NMDA glutamate receptor antagonist, ketamine, that acutely produces symptoms and cognitive performance changes in normal healthy adults that are milder versions of those seen in patients with schizophrenia. The experiment also aimed to increase the interpretability of the ketamine paradigm through the use of steady-state ketamine plasma levels, as well as comprehensive clinical and cognitive assessments. The study was a double-blind, placebo-controlled, randomized, within-subjects comparison of 3 fixed doses of intravenous ketamine in healthy young adult men, hypothesizing dose-dependent ketamine-induced increases in both "positive" and "negative" schizophrenia-like symptoms, and dose-dependent decreases in hippocampally-associated memory performance.

\section{METHODS}

\section{Subjects}

The research protocol was approved by the Human Studies Committee at Washington University School of Medicine. All subjects gave written informed consent prior to participation, were recruited using local advertisement, and were screened for psychiatric disorders and for general medical health. Only males were studied because available pharmacokinetic data on ketamine is almost exclusively from males and this study required calculation of predicted plasma concentrations in relation to a ketamine dose. In addition, there is a lower threshold for NMDA receptor antagonist mediated neurotoxicity in female rats (Olney et al. 1989) and this study sought a maximum safety margin (see Ketamine Dosing and Safety Considerations below). Sub- 
jects were interviewed using the Diagnostic Instrument for Genetic Studies (Nurnberger et al. 1994). A senior clinician reviewed all data to determine whether subjects met criteria for any DSM-IV diagnoses. Subjects were also interviewed with the Family Instrument for Genetic Studies (Nurnberger et al. 1994) in order to identify relevant psychopathology within first degree relatives; none was detected in this sample.

The inclusion criteria were: i) male adults; ii) aged 18 to 40 years; and iii) able to give informed consent. The exclusion criteria were: i) any Axis I or Cluster A Axis II psychiatric disorders, including any substance use disorders within the past 12 months; and ii) the presence of any medical disorder that can confound the assessment of symptoms, relevant biologic treatments or measures, or diagnosis; the following conditions are currently identified: insulin- or non-insulin-dependent diabetes mellitus; hypertension (treated or untreated); glaucoma, dehydration, epilepsy, endocrine disorders, any intra-abdominal, limb or intrathoracic surgery within the prior 6 months; any diagnosed cardiac condition causing documented hemodynamic compromise or dysfunction of the SA or AV node, any diagnosed respiratory condition causing documented or clinically recognized hypoxia (e.g., chronic obstructive or restrictive pulmonary disease), fever, body weight $<80 \%$ or $>$ $120 \%$ of ideal body weight, or any medical condition known to interfere with cognitive performance; medication-related exclusions included narcotics, corticosteroids or spironolactone, benzodiazepines or any other sedative-hypnotics, or any medication that interferes with SA or AV node function; iii) any past use of PCP or ketamine; and iv) Mental Retardation as determined by DSM-IV criteria. Fifteen healthy subjects $(n=15)$ met all criteria and participated in the study. Clinical characteristics of the sample were as follows (mean \pm S.D.): age $=21.7 \pm 3.2$; years of education $=14.7 \pm 2.2$; handedness (decile score; Oldfield 1971) $=6.3 \pm 2.7$; and body mass index $\left(\mathrm{kg} / \mathrm{m}^{2}\right)=22.4 \pm 3.4$.

Subjects all used English as a primary language and included 10 white Americans, 3 black Americans, 1 Hispanic American, and 1 Asian American.

\section{Procedure}

The study was a double-blind, placebo-controlled, randomized, within-subjects comparison of 3 fixed subanesthetic, steady-state doses of intravenous (IV) ketamine in healthy young adult men. Blinded clinical assessments and a comprehensive cognitive battery were administered during each of the 4 infusion conditions conducted across 4 different mornings. In addition, subjects received abbreviated clinical assessments prior to each infusion, at the completion of each study day (60 minutes post-infusion), and approximately 48 hours post-infusion. Each condition was administered on non-consecutive days to maximize safety (mean days between sessions $2.6 \pm 1.1$ ).

At 8:00 AM on each study day, subjects came to the General Clinical Research Center (GCRC) at Washington University School of Medicine after an at least 8-hour overnight fast. Subjects were fasted in order to minimize the potential confound of varying glucose levels on NMDA receptor-related function and on direct measures of cognitive function (Izumi et al. 1993; Craft et al. 1993; Newcomer et al. 1994a; Newcomer et al. in press; Craft et al. 1996). Ketamine (or $0.9 \%$ normal saline "placebo" solution) was infused intravenously at specified loading dose and maintenance infusion rates (see below) using a Harvard pump apparatus, while $0.9 \%$ normal saline was used to maintain a separate patent draw line. Following administration of the loading dose over 10 minutes, maintenance infusions were begun. Clinical assessments were anchored at 30 minutes after infusions started, allowing an additional 20 minutes after completion of loading prior to the blinded behavioral and cognitive evaluation (safety and adjunctive clinical assessments were performed during this initial period); cognitive testing began after completion of this clinical battery. The rationale for this additional stabilization period included the need to allow for ketamine distribution to occur (distribution half-life is approximately 7 minutes; Zsigmond and Domino 1990), and the need to allow changes in vascular and extravascular compartments to affect brain function. In all conditions, pulse, blood pressure, pulse-oximetry, and an electrocardiogram strip were continuously monitored for safety, with values recorded at $0,20,60$, and 120 minutes after starting the infusion. Blood samples were obtained at the same time points in order to provide plasma measurements to assist in interpreting the cognitive/behavioral data.

\section{Clinical Assessments}

Full clinical assessments using the following battery were performed blind to treatment assignments during the infusion: a) the Brief Psychiatric Rating Scale (BPRS; Overall 1974), an 18-item scale of psychiatric symptoms that is sensitive to symptom change, with classic subfactor scores used for the analysis (Hedlund and Vieweg 1980); b) the Scale for the Assessment of Negative Symptoms (SANS), a 25-item scale that assesses different aspects of the negative symptom construct (Andreasen 1982); and c) a clinician administered Clinical \& Adverse Events Checklist, a five-point Likert scale composed of items identified in published anesthesiology and other clinical literature concerning the effects of ketamine. An abbreviated unblinded assessment was performed at the pre- and post-infusion ratings using the BPRS and Clinical \& Adverse Events Checklist. Of note, for the "hallucinatory behavior" item on the BPRS 
we used the original item description to rate "perceptions without normal external stimulus correspondence ... distinctly different from the thought and imagery processes of normal people", so that both perceptual distortions and hallucinations could be scored for this item.

\section{Cognitive Measures}

Different versions of each of the cognitive tasks, matched for difficulty, were administered on each study day. An exception to this was the sustained attention task which involved randomized stimulus presentation. Two different sets of the task battery, offering the different task versions in two different orders across study days, were counterbalanced across subjects. The tasks were presented in a fixed order in both sets: paragraph recall (immediate); delayed match to sample (task-a); stroop; continuous performance task; paragraph recall (delayed); verbal fluency; spatial delayed response, and delayed match to sample (task-b).

\section{Declarative Memory Measures}

Immediate and Delayed Paragraph Recall. This was measured using the paragraph recall test (Wechsler 1945; Wechsler 1987), a validated (Squire 1987) and sensitive measure (Butters et al. 1978; Storandt et al. 1984) of verbal declarative memory performance. Subjects hear two recorded narratives, each with 44 pieces of information, followed by immediate and delayed (30 min) verbatim recall. Eight paragraphs were used which have been shown to be comparable in recall and sensitivity (unpublished data). Scores for both correct and inaccurate recall were tabulated based on a modification of established scoring methods (Russell 1975; Gangarosa et al. 1988). Immediate and delayed total correct scores for verbatim recall and commission errors were analyzed.

Delayed Match to Sample (DMS). A computerized delayed pattern match to sample task was used to measure non-verbal declarative memory performance, based on previous work with hippocampally lesioned animals (Winocur 1978; Aggleton et al. 1988) and humans (Sidman et al. 1968). There are two subtasks, "a" and " $b$ ". In the first (" $a$ ") there are 10 consecutive presentations of two geometric line drawings for a total of 20 drawings, followed by a 3.5 minute delay filled with a digit span task. Following the delay, subjects are presented with 10 recognition trials with one target and two distractor drawings per trial. The second (" $\mathrm{b}$ ") subtask involves the presentation of 20 consecutive stimuli of 2 drawings each. Subjects are then presented with 10 recognition trials with one target and two distractors per trial. The targets are the first 10 presented stimuli only. Number of correct responses/total possible re- sponses (10 per task), as well as reaction time, were calculated for the analysis.

\section{Selective Attention}

A multiple version modification of the Stroop color-word interference task (Golden 1978) was used as a measure of selective attention that detects impairments in schizophrenia (Cannon et al. 1994). The total time to complete each condition and the number of incorrect responses per condition were analyzed.

\section{Sustained Attention}

Sustained attention was measured using a computer generated continuous performance task (CPT) that presents a rapid, continual sequence of letters. Subjects must press a key whenever a specific letter appears on the screen. Accuracy and reaction time were measured.

\section{Working Memory/Frontal Function}

Word List Generation (Verbal Fluency) Task. This task was used as a measure of prefrontal cortical function (Milner 1964). The total number of correct responses were analyzed.

Spatial Delayed Response (SDR). This task was used to measure subjects' spatial working memory at short delays and spatial working/spatial declarative memory at long delays. Animals and humans with medial temporal lobe damage are able to perform accurately on trials with short delays, yet are impaired on trials with longer delays (Backer-Cave and Squire 1992; Kowalska 1995; Rains and Milner 1994; Zola-Morgan and Squire 1985). In general, delays greater than 15-30 seconds on similar tasks are sensitive to medial temporal dysfunction (Alvarez et al. 1994; Rains and Milner 1994; Squire et al. 1988). Working memory for spatial location has been well-researched in primates (e.g., Funahashi et al. 1989). This methodology was modified for use with humans (Luciana et al. 1992; Hershey et al. 1998). Mean error (distance from a target on a computer screen) was calculated for each subject at each type of trial (5 second delay, 120 second delay, and cue-present [no recall] trials).

\section{Ketamine Dosing and Safety Considerations}

Loading doses and maintenance infusion rates were calculated using published pharmacokinetic parameters for ketamine (Goodman Gillman et al. 1990) in order to produce three different targeted steady-state plasma ketamine levels ( $150 \mathrm{ng} / \mathrm{ml} ; 45 \mathrm{ng} / \mathrm{ml} ; 13.5 \mathrm{ng} /$ $\mathrm{ml})$. The high dose condition aimed to replicate plasma levels at time points associated with measured symptom production during Krystal et al.'s "high" dose infu- 
sion (Krystal et al. 1994). We administered loading doses over 10 minutes in order to maximize safety. Loading doses were $0.27 \mathrm{mg} / \mathrm{kg}, 0.081 \mathrm{mg} / \mathrm{kg}$, and $0.0243 \mathrm{mg} / \mathrm{kg}$, respectively. Maintenance infusions were begun immediately after the loading dose was administered. Maintenance infusion rates were 0.00225 $\mathrm{mg} / \mathrm{kg} / \mathrm{min}, 0.000675 \mathrm{mg} / \mathrm{kg} / \mathrm{min}$, and $0.0002025 \mathrm{mg} /$ $\mathrm{kg} / \mathrm{min}$, respectively.

Ketamine is an FDA-approved anesthetic agent that has been in clinical and/or investigational use for approximately 25 years, frequently in pediatric or poor risk populations. The safety of a ketamine infusion is predicated on careful dose selection to avoid undesirable effects. Because available pharmacokinetic data is almost exclusively from males and this study required pharmacokinetic calculations, only males were studied. The safety of the procedure is underscored by the use of a high dose that is well below the typically used anesthetic dose in clinical practice. Olney et al. (1989) have reported that treatment of adult rats with ketamine can produce a reversible toxic reaction in certain cerebrocortical neurons. The threshold intraperitoneal dose for producing a minimal reaction in the rat is $40 \mathrm{mg} / \mathrm{kg}$. Since this dose is 74 times higher than the highest total dose $(0.27 \mathrm{mg} / \mathrm{kg}+[0.00225 \mathrm{mg} / \mathrm{kg} / \mathrm{min} \times 120 \mathrm{~min}]=$ $0.54 \mathrm{mg} / \mathrm{kg}$ ) used in this experiment, the safety margin is substantial, even after allowing for possible interspecies differences. The highest loading dose used in this experiment $(0.27 \mathrm{mg} / \mathrm{kg})$ is approximately $1 / 5$ the loading dose $(1-2 \mathrm{mg} / \mathrm{kg})$ used in human anesthesia, and is a dose which has been used in healthy subjects without residual cognitive, physical or behavioral effects following the day of administration, even when given on consecutive experimental days (Krystal et al. 1994).

\section{Plasma Assays}

Blood samples were placed on ice, plasma was rapidly obtained from blood by centrifugation, and samples were stored at $-80^{\circ} \mathrm{C}$. The principal active fraction for ketamine includes ketamine and norketamine (Reich and Silvay 1989), which were both measured using gas chromatography (National Medical Services, Philadelphia, PA). In addition, ketamine is known to produce increases in plasma cortisol (Krystal et al. 1994; Fahringer et al. 1974; Clarke et al. 1974; Oyama et al. 1970) and glucose (Kaniaris et al. 1975; Clarke et al. 1974), and this group has reported cognitive effects of glucose and insulin (Newcomer et al. 1994a; Newcomer et al. in press; Craft et al. 1993; Craft et al. 1996) and glucocorticoids (Newcomer et al. 1994b) in humans, motivating the measurement of these variables to rule out confounds to the interpretation of cognitive effects. For similar reasons, plasma epinephrine and norepinephrine were measured with a single isotope derivative (ra- dioenzymatic) method (Shah et al. 1985). Plasma glucose was measured with a glucose oxidase method using a glucose analyzer (Beckman Instruments, Fullerton, CA). Plasma insulin (Kuzuya et al. 1977) and cortisol (Farmer and Pierce 1974) concentrations were measured by radio-immunoassay.

\section{Analysis}

The primary hypotheses concerning ketamine effects on positive and negative symptoms were first tested using ANOVAs evaluating relevant symptom change within ("time", i.e., baseline, infusion, post-infusion) and across treatment conditions ("treatment condition", i.e., placebo, low dose, moderate dose, high dose), seeking a significant interaction between treatment condition and time. The primary hypotheses concerning ketamine induction of positive and negative symptoms as well as ketamine-induced decreases in hippocampally-associated memory performance were then tested using ANOVAs evaluating blinded symptom and cognitive change across the steady-state treatment conditions, seeking a significant effect of treatment condition. An additional factor of task condition (e.g., immediate versus delayed recall) was added to the ANOVAs evaluating paragraph recall and delayed match to sample tasks. The a priori hypotheses concerning positive and negative symptoms and memory performance were evaluated using a limited number of planned ANOVA tests for the effect of treatment condition, with each test addressing a distinct measure of the positive, negative or memory constructs (e.g., verbal versus non-verbal memory). Accordingly, adjustments of the critical significance level for these tests are not essential. However, this is not the case for multiple tests conducted in more exploratory analyses concerning other BPRS subscales (e.g., anxiety-depression subscale), SANS subscales, plasma variables and the assessment of ketamine effects on additional cognitive tasks. For these tests, adjusted (Bonferroni) P-values are offered throughout the Results section, along with unadjusted values, for the reader's consideration. Univariate ANOVAs were used to supplement the multivariate ANOVAs when missing data points were encountered; the results of the multivariate and univariate ANOVAs were consistent except as noted and univariate analyses are reported. All but one subject on one treatment day completed almost all of the cognitive battery, however, several subjects had missing or invalid data points for some of the computer tasks due to technical problems (e.g., CPT reaction time data was filtered for outliers). Significant effects of treatment condition were further evaluated using paired t-tests to assess change across individual dose levels. Potential confounds were evaluated using MANOVAs to test the effect of individual covariates (e.g., plasma cortisol during each treatment condition at the time point 
closest to the behavioral/cognitive variable) on the primary results.

\section{RESULTS}

\section{Behavioral Results}

Ketamine, under these dosing conditions, produced mild dose-dependent positive and negative schizophrenia-like symptoms. Testing the effect of treatment condition on total BPRS scores across baseline, maintenance infusion, and post-washout time points, indicated a significant treatment condition $\times$ time interaction (Figure 1). Evaluating individual BPRS subscale scores across baseline, maintenance infusion, and postwashout time points, "positive" symptom subscale scores (hallucinatory behavior, conceptual disorganization, and unusual thought content) accounted for the largest effect (treatment condition $\times$ time interaction $(\mathrm{F}[6,83]=22.54 ; \mathrm{p}=0.0001)$, with similar ketamine-induced increases in "negative" symptom subscale scores (blunted affect, emotional withdrawal, and motor retardation; treatment condition $\times$ time interaction: $F[6,83]=$ 2.73; $\mathrm{p}=0.02$ ).

In the analysis of blinded clinical ratings for each study day during the steady-state conditions, BPRS total score demonstrated a significant effect of treatment condition $(\mathrm{F}[3,42]=21.60 ; \mathrm{p}=0.0001)$ which was further explained by increases in positive and negative symptoms, and some additional symptomatology.

Positive Symptoms. An effect of treatment condition was demonstrated for BPRS positive symptom subscale scores (Figure 2). Illustrating experiences during "high" dose ketamine infusions, subjects commented: "It's as though green emerald is like in and around me ..."; "My hand looks like a midget hand ... like a funhouse

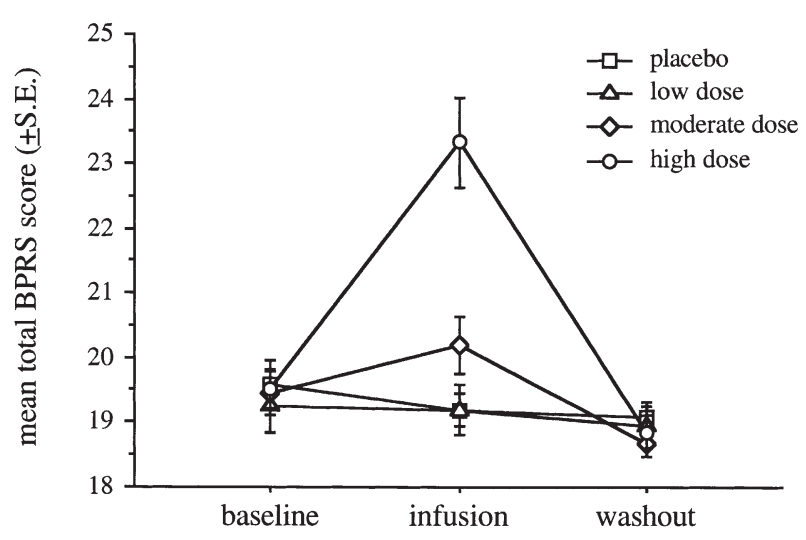

Figure 1. Ketamine-induced increases in total BPRS symptoms during experimental infusion conditions in young healthy adult males $(\mathrm{N}=15)$ (treatment condition $\times$ time interaction: $F[6,83]=17.62 ; p=0.0001)$.

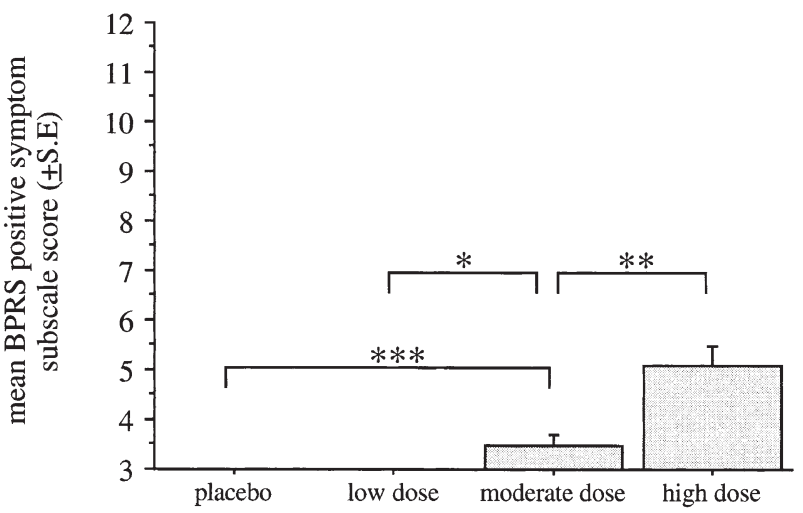

Figure 2. Dose-dependent ketamine-induced increases in BPRS positive symptoms in young healthy adult males $(\mathrm{N}=$ 15) (main effect of treatment condition: $\mathrm{F}[3,42]=21.84 ; \mathrm{p}<$ $0.0001) * \mathrm{t}(14)=5.07, \mathrm{p}=0.0001 ;{ }^{* *} \mathrm{t}(14)=4.99, \mathrm{p}=0.0001$; $* * * t(14)=2.17, \mathrm{p}=0.02$.

mirror effect." Another subject reported seeing the "shadow" of a person falling past the fourth floor window of our study room.

Negative Symptoms. An effect of treatment condition was detected for BPRS negative symptom subscale scores $(\mathrm{F}[3,42]=2.89 ; \mathrm{p}=0.047)$, as well as for Scale for the Assessment of Negative Symptoms (SANS) total scores (Figure 3). BPRS negative symptoms increased between placebo and "high" dose (t[14] = -1.95; $\mathrm{p}=0.04)$, "low" and "moderate" doses $(\mathrm{t}[14]=-2.26 ; \mathrm{p}=0.02)$ and "low" and "high" doses (t[14] $=-2.32 ; \mathrm{p}=0.02)$. In an exploratory analysis, several SANS subscales were found to contribute to the effect on the total SANS score (Table 1; Bonferroni critical $\mathrm{p}=0.01$ ).

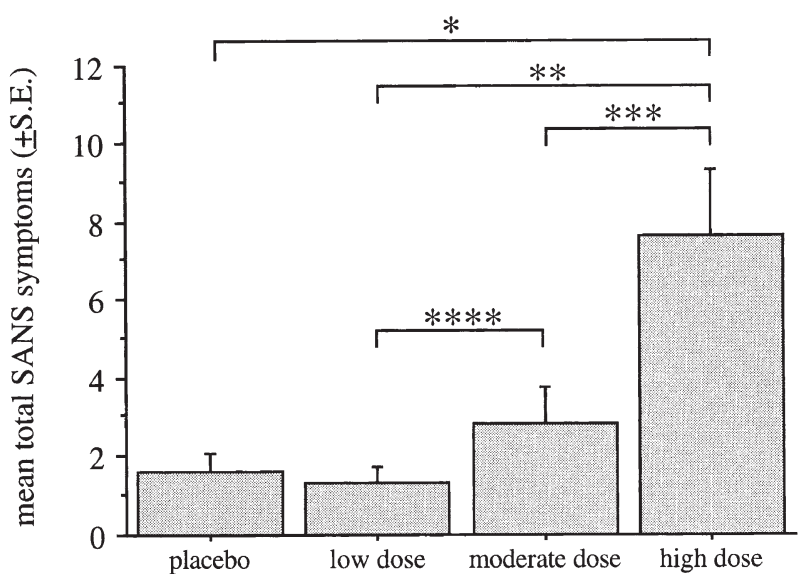

Figure 3. Dose-dependent ketamine-induced increases in total SANS symptoms in young healthy adult males $(\mathrm{N}=$ 15) (main effect of treatment condition: $F[3,42]=10.55, p<$ $0.0001) ;{ }^{*} \mathrm{t}(14)=4.44, \mathrm{p}=0.0003 ;{ }^{* *} \mathrm{t}(14)=4.18, \mathrm{p}=0.0005$; ${ }^{* * *} \mathrm{t}(14)=2.54, \mathrm{p}=0.01 ;{ }^{* * * *} \mathrm{t}(14)=1.61, \mathrm{p}=0.07$. 
Table 1. Mean ( \pm S.D.) Performance on SANS Subscales During Steady-State Ketamine Infusion Conditions in Healthy Males $(\mathrm{n}=15)$

\begin{tabular}{lccccl}
\hline SANS & Placebo & Low Dose & Moderate Dose & High Dose & \\
\hline Affective flattening & $0.2 \pm 0.6$ & $0.0 \pm 0.0$ & $0.7 \pm 1.1$ & $1.4 \pm 2.1$ & $\mathrm{~F}[3,42]=4.49 ; \mathrm{p}=0.008$ \\
Alogia & $0.0 \pm 0.0$ & $0.1 \pm 0.3$ & $0.3 \pm 0.6$ & $0.6 \pm 1.1$ & $\mathrm{~F}[3,42]=2.51 ; \mathrm{p}=0.07$ \\
Avolition-apathy & $0.2 \pm 0.6$ & $0.2 \pm 0.6$ & $0.5 \pm 0.9$ & $1.5 \pm 1.5$ & $\mathrm{~F}[3,42]=9.08 ; \mathrm{p}=0.0001$ \\
Anhedonia-asociality & $0.3 \pm 0.9$ & $0.2 \pm 0.6$ & $0.8 \pm 2.0$ & $2.9 \pm 3.2$ & $\mathrm{~F}[3,42]=6.51 ; \mathrm{p}=0.001$ \\
Attention & $0.9 \pm 1.1$ & $0.9 \pm 1.2$ & $0.5 \pm 0.7$ & $1.3 \pm 1.3$ & $\mathrm{~F}[3,42]=2.61 ; \mathrm{p}=0.06$ \\
\hline
\end{tabular}

Other Symptoms. Ketamine also produced mild increases in symptoms of language and speech disturbance and disorganization. SANS alogia subscale (poverty of speech, content of speech, blocking, increased latency of response) scores were increased between placebo and both "moderate" $(\mathrm{t}[14]=-1.74 ; \mathrm{p}=0.05)$ and "high" doses (t[14] $=-2.07 ; \mathrm{p}=0.03)$ and between "low" and "high" doses (t[14] $=-1.74 ; \mathrm{p}=0.05)$, with a trend $(\mathrm{F}[3,42]=2.51 ; \mathrm{p}=0.07$; Bonferroni critical $\mathrm{p}=$ 0.01 ) towards an overall effect of treatment on alogia subscale scores. The thought and language disturbance was retrospectively described by one subject as, "I couldn't think of the words that I wanted to say . . . words had no meaning", while another subject reported " ... it was as though you were speaking gibberish." An effect of treatment was also detected for the BPRS anxiety-depression subscale $(F[3,42]=5.73 ; \mathrm{p}=$ 0.002; Bonferroni critical $p=0.0125$ ), accounted for by increases in "somatic concern". Overall, the clinical syndrome produced was mild in intensity and subjects remained comfortable, alert and oriented. No evidence of any persistent abnormal symptoms was detected at the 48-hour post-infusion assessment.

\section{Cognitive Results}

Ketamine treatment produced a dose-dependent decrease in learning and memory performance on both a verbal and non-verbal declarative memory task.

Paragraph Recall. Analysis indicated an effect of treatment condition on overall paragraph recall performance (Figure 4), with an expected main effect of recall condition (immediate vs. delay; $F[1,14]=46.14 ; \mathrm{p}=$ 0.0001 ), but no significant interaction of treatment condition with recall condition. Consistent with the lack of a treatment interaction with recall condition, similar treatment effects were noted for both immediate $(\mathrm{F}[3,41]=3.92 ; \mathrm{p}=0.02)$ and delayed $(\mathrm{F}[3,41]=5.03$; $\mathrm{p}=0.005)$ paragraph recall performance. The mean decrease in performance on total correct recall (immediate + delayed) from placebo to "high" dose (21.2) amounted to a $18.6 \%$ decrease in recall performance.

DMS. A significant effect of treatment condition was also apparent for performance on the DMS task (Figure 5), again with no significant interaction with recall condition. This effect was detected in the univariate ANOVA but was not significant in the multivariate analysis (requiring complete data for each subject for that subject's data to be included) where the number of subjects with complete data across all conditions was reduced.

Other Cognitive Tasks. No significant effects of treatment condition, using adjusted or unadjusted p-values, were detected on any other measures of cognitive performance, including performance on the modified Stroop task, the CPT, the verbal fluency task, or the SDR task.

\section{Additional Clinical and Adverse Events, and Safety Measures}

Consistent with previous reports (White et al. 1982; Reich and Silvay 1989), ketamine transiently increased diastolic and systolic blood pressure, and produced very short-lived increases in pulse rate that were not evidenced by the 20 minute time point; no decrease in blood oxygen saturation was seen. Six subjects experienced nausea during the high dose condition, and one

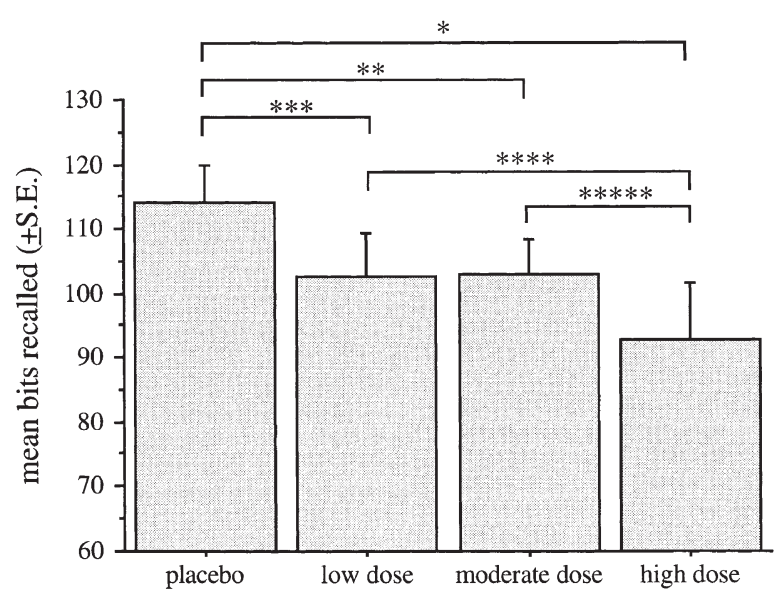

Figure 4. Dose-dependent ketamine-induced decreases in total (immediate + delayed) paragraph recall scores in young healthy adult males $(\mathrm{N}=15)$ (main effect of treatment condition: $\mathrm{F}[3,41]=5.11, \mathrm{p}=0.004 ;{ }^{*} \mathrm{t}(13)=3.30, \mathrm{p}=$ $0.003 ;{ }^{* *} \mathrm{t}(14)=2.47, \mathrm{p}=0.01 ;{ }^{* *} \mathrm{t}(14)=2.02, \mathrm{p}=0.03$; ${ }^{* * * *} \mathrm{t}(13)=1.70, \mathrm{p}=0.06 ;{ }^{* * * *} \mathrm{t}(13)=1.57, \mathrm{p}=0.07$. 


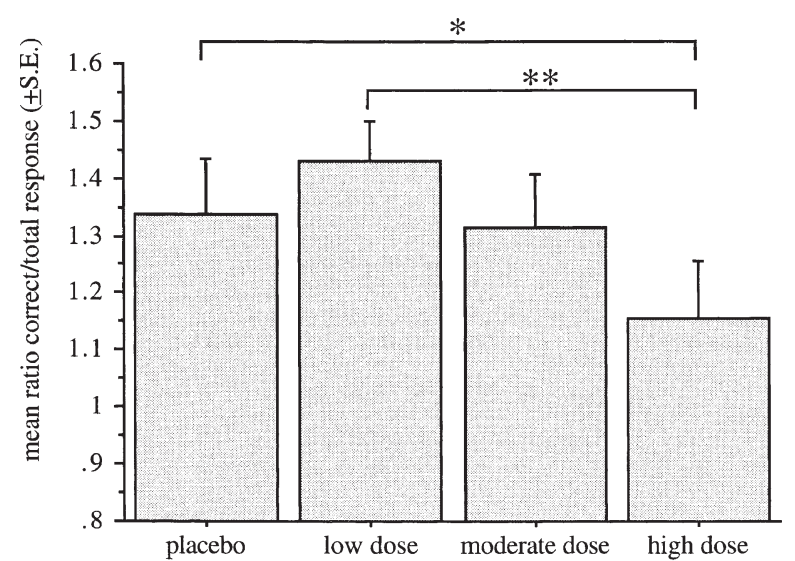

Figure 5. Dose-dependent ketamine-induced decreases in total $(a+b)$ delayed matched to sample performance in young healthy adult males $(\mathrm{N}=15)$ (main effect of treatment condition: $\mathrm{F}[3,40]=2.93 ; \mathrm{p}=0.045) ;{ }^{*} \mathrm{t}(5)=2.04, \mathrm{p}=$ $0.05 ;{ }^{* *} \mathrm{t}(7)=2.78, \mathrm{p}=0.01$.

at the moderate dose, with 2 subjects vomiting. One subject with nausea at the higher dose could not perform all of the cognitive assessments and missed a final blood sample. During the loading dose, ketamine dosedependently increased feelings of drowsiness, difficulty concentrating, dizziness, confusion, lightheadedness, "high", exhilaration, floating sensations, parasthesias, "dream-like state", and change in sense of time, with all symptoms remaining at moderate levels or below. During the steady-state conditions, ketamine produced dose dependent feelings of drowsiness, difficulty concentrating, dizziness, lightheadedness, "high", "dreamlike state", and change in sense of time, with all symptoms at mild levels or below. Notably, cognitive effects could not be explained by sedation. Covarying "drowsiness" in the ANOVA models testing the effect of ketamine on verbal and non-verbal memory performance indicated no main effect of drowsiness level or interactions between drowsiness and treatment condition for either the paragraph recall or DMS tasks.

\section{Plasma Results}

Stable, steady-state plasma ketamine conditions were produced in both the moderate and high dose treatment conditions, with low dose plasma levels below detectable limits for the assay (Figure 6). Ketamine plasma concentrations peaked at the 20-min plasma sample and then decreased to a stable steady-state plasma level across the 60 and 120-min samples. Conservative calculations using the measured ketamine levels at 20 and 60 minutes and ketamine's well-known distribution and elimination half lives established that steady-state levels were obtained by 30 minutes (Figure 6), indicating that the complete battery of assessments occurred dur-

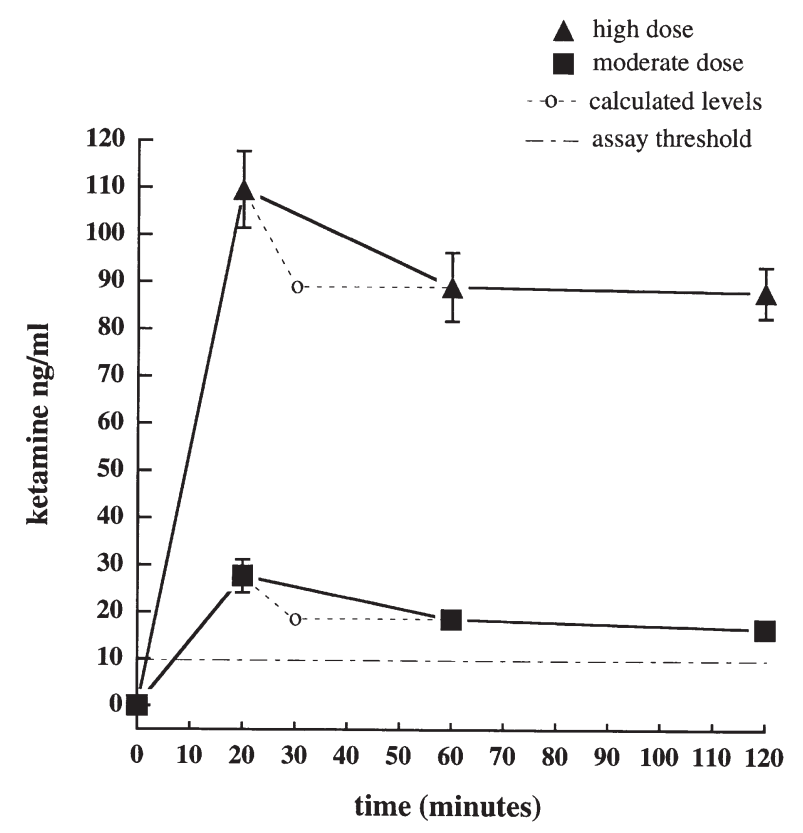

Figure 6. Plasma ketamine concentrations across treatment conditions in healthy males $(\mathrm{N}=15)$, indicating steady-state conditions beginning at 30 minutes. Calculated levels were based on measured ketamine levels at 20 and 60 minutes and ketamine's distribution and elimination half-lives (condition $\times$ time interaction: $\mathrm{F}[9,125]=73.62 ; \mathrm{p}=0.0001)$.

ing steady-state conditions. In contrast, plasma norketamine levels rose steadily over the period of the infusion (Table 2). However, determination of NMDA receptor antagonist activity for norketamine indicated that this compound is 7-10 times less potent than ketamine (Farber and Olney, unpublished data), so that even terminal norketamine levels were unlikely to contribute significantly to any NRH-induced clinical effects. Significant treatment condition $\times$ plasma sample time interactions were detected for epinephrine, norepinephrine, glucose, and cortisol concentrations (Table 2; Bonferroni critical $\mathrm{p}=0.01$ ). Covarying plasma concentrations of these potentially cognitively active variables from relevant time points in models testing the effect of ketamine on verbal and non-verbal memory performance indicated no main effect or interaction with treatment condition for any variable with either paragraph recall or DMS performance.

\section{DISCUSSION}

Ketamine infusions in healthy adult men produced mild dose-dependent increases in schizophrenia-like psychiatric symptoms, consistent with previous reports (Krystal et al. 1994; Malhotra et al. 1996). Measuring cognitive performance with a comprehensive battery, ketamine infusions additionally produced robust, dose- 
Table 2. Mean ( \pm S.D.) Plasma Levels During Steady-State Ketamine Infusion Conditions in Healthy Males $(\mathrm{n}=15 ; \mathrm{NS}>0.10)$

\begin{tabular}{|c|c|c|c|c|c|}
\hline & Placebo & Low Dose & Moderate Dose & High Dose & $\begin{array}{c}\text { Treatment Condition } \\
\times \text { sample time }\end{array}$ \\
\hline \multicolumn{6}{|c|}{ Norketamine (ng/ml) } \\
\hline $0^{\prime}$ & - & - & $0.0 \pm 0.0$ & $0.0 \pm 0.0$ & \multirow{4}{*}{$\begin{array}{l}F[9,125]=85.69 \\
p=0.0001\end{array}$} \\
\hline $20^{\prime}$ & - & - & $16.9 \pm 8.8$ & $37.5 \pm 19.2$ & \\
\hline $60^{\prime}$ & - & - & $20.9 \pm 3.9$ & $64.3 \pm 11.9$ & \\
\hline $120^{\prime}$ & - & - & $23.3 \pm 4.2$ & $79.5 \pm 19.0$ & \\
\hline \multicolumn{6}{|c|}{ Epinephrine (pg/ml) } \\
\hline $0^{\prime}$ & $45.1 \pm 32.8$ & $36.9 \pm 30.2$ & $40.1 \pm 29.7$ & $30.4 \pm 17.9$ & \multirow{4}{*}{$\begin{array}{l}F[9,125]=2.38 \\
p=0.02\end{array}$} \\
\hline $20^{\prime}$ & $38.4 \pm 24.2$ & $33.7 \pm 17.3$ & $44.1 \pm 30.3$ & $170.1 \pm 308.2$ & \\
\hline $60^{\prime}$ & $41.9 \pm 27.8$ & $38.9 \pm 25.5$ & $42.9 \pm 26.8$ & $87.3 \pm 65.7$ & \\
\hline $120^{\prime}$ & $39.7 \pm 24.0$ & $32.1 \pm 21.5$ & $41.7 \pm 27.7$ & $64.5 \pm 47.3$ & \\
\hline \multicolumn{6}{|c|}{ Norepinephrine $(\mathrm{pg} / \mathrm{ml})$} \\
\hline $0^{\prime}$ & $180.3 \pm 99.3$ & $188.2 \pm 88.3$ & $188.8 \pm 108.3$ & $145.1 \pm 58.0$ & \multirow{4}{*}{$\begin{array}{l}F[9,125]=10.50 \\
p=0.0001\end{array}$} \\
\hline $20^{\prime}$ & $174.4 \pm 95.5$ & $194.5 \pm 96.1$ & $200.1 \pm 111.5$ & $308.3 \pm 155.1$ & \\
\hline $60^{\prime}$ & $170.3 \pm 72.1$ & $165.5 \pm 59.3$ & $156.3 \pm 54.1$ & $176.1 \pm 65.7$ & \\
\hline $120^{\prime}$ & $173.9 \pm 66.4$ & $187.1 \pm 84.1$ & $168.5 \pm 59.4$ & $167.6 \pm 63.2$ & \\
\hline \multicolumn{6}{|c|}{ Insulin $(\mu \mathrm{U} / \mathrm{ml})$} \\
\hline $0^{\prime}$ & $7.3 \pm 2.4$ & $6.2 \pm 2.6$ & $6.4 \pm 2.9$ & $6.1 \pm 3.6$ & \multirow{4}{*}{ NS } \\
\hline $20^{\prime}$ & $6.7 \pm 3.7$ & $6.8 \pm 2.8$ & $6.8 \pm 3.3$ & $5.6 \pm 3.4$ & \\
\hline $60^{\prime}$ & $6.3 \pm 2.8$ & $5.9 \pm 2.5$ & $6.5 \pm 3.0$ & $7.6 \pm 6.2$ & \\
\hline $120^{\prime}$ & $6.4 \pm 2.9$ & $5.7 \pm 2.3$ & $6.1 \pm 3.6$ & $6.6 \pm 4.5$ & \\
\hline \multicolumn{6}{|c|}{ Glucose (mg/dl) } \\
\hline $0^{\prime}$ & $91.0 \pm 7.0$ & $88.1 \pm 5.9$ & $88.5 \pm 9.1$ & $88.8 \pm 7.0$ & \multirow{4}{*}{$\begin{array}{l}F[9,125]=3.10 \\
p=0.002\end{array}$} \\
\hline $20^{\prime}$ & $90.4 \pm 7.3$ & $88.0 \pm 6.5$ & $89.7 \pm 7.7$ & $92.2 \pm 9.5$ & \\
\hline $60^{\prime}$ & $92.0 \pm 6.9$ & $89.9 \pm 7.9$ & $90.8 \pm 9.4$ & $96.6 \pm 15.0$ & \\
\hline $120^{\prime}$ & $88.5 \pm 6.9$ & $87.3 \pm 7.3$ & $89.4 \pm 6.3$ & $95.3 \pm 10.2$ & \\
\hline \multicolumn{6}{|c|}{ Cortisol ( $\mu \mathrm{g} / \mathrm{dl})$} \\
\hline $0^{\prime}$ & $16.7 \pm 6.9$ & $14.6 \pm 4.9$ & $15.3 \pm 4.9$ & $13.7 \pm 5.4$ & \multirow{4}{*}{$\begin{array}{l}F[9,125]=8.84 \\
p=0.0001\end{array}$} \\
\hline $20^{\prime}$ & $14.2 \pm 6.7$ & $12.9 \pm 4.0$ & $13.8 \pm 4.7$ & $18.3 \pm 5.6$ & \\
\hline $60^{\prime}$ & $12.0 \pm 4.8$ & $10.9 \pm 4.9$ & $11.3 \pm 4.3$ & $21.4 \pm 10.0$ & \\
\hline $120^{\prime}$ & $10.5 \pm 4.4$ & $10.3 \pm 5.2$ & $9.1 \pm 2.9$ & $22.1 \pm 12.4$ & \\
\hline
\end{tabular}

dependent impairment in verbal, and preliminary evidence for impairment in non-verbal, declarative memory performance. Notably, the effect of ketamine on memory performance occurred at and below plasma concentrations producing other schizophrenia-like symptoms. These results complement previous reports of ketamine-induced memory impairment in humans (Harris et al. 1975; Ghoneim et al. 1985; Krystal et al. 1994; Malhotra et al. 1996), and extend those reports by defining the dose-dependence of this effect on a well-validated measure and by suggesting a preferential effect on declarative memory, versus other differentiated elements of cognitive performance, at these steady-state plasma conditions. The results are relevant to an NMDA receptor hypofunction (NRH) model of schizophrenia (Olney and Farber 1995) and suggest that progressively increasing levels of NRH are associated with an early occurring and prominent impairment of memory performance, consistent with evidence for an early and prominent memory impairment in schizophrenia.

This experiment defined steady-state ketamine conditions associated with multiple schizophrenia-like symptoms, with dose-dependent increases in positive and negative symptoms as well as memory impair- ment, and with the higher dose condition producing the most complete syndrome. Notably, dose-dependent ketamine effects on BPRS positive symptoms, SANS negative symptoms, and verbal declarative memory performance were all robustly significant, even applying conservative Bonferroni adjustments to correct for additional tests on related measures (critical Bonferroni $p=0.025,0.025$, and 0.017 , respectively). Consistent with previous reports, the effects of ketamine across this dose range were mild, well-tolerated and without detectable residual effects, providing further evidence that such doses can be used safely in healthy young males within the confines of similar closely monitored experimental paradigms. The dose-dependency of these effects suggests that higher doses of ketamine than those used in this study may be associated with larger and clinically significant effects within these domains, or effects on additional cognitive or behavioral variables. This study did not detect formal thought disorder or language disorganization during the conditions tested, with the exception of modest effects on the alogia subscale of the SANS. While the assessments may not have included the most sensitive measures of such symptoms, blocking, loosening of associations, and lan- 
guage disorganization were all noted during the loading doses, indicating that these symptoms could be more obvious at higher plasma concentrations. This observation suggests that formal thought and language disturbances may be associated with more extensive $\mathrm{NRH}$ than that required for the production of the positive and negative symptoms or memory impairment.

Subanesthetic doses of ketamine produced dosedependent impairments in learning and memory performance on a verbal and a non-verbal declarative memory task. The similar effect of ketamine on both immediate and delayed paragraph recall, and on both versions of the DMS task, is consistent with animal studies and suggests that NMDA receptor antagonism or hypofunction can affect neural mechanisms regulating encoding. No similar effect was detected on the 120-second delay condition of the SDR task, underscoring differences in the sensitivity or difficulty of different tasks as well as differences in the type of memory performance being measured. Measuring other major differentiated elements of cognitive function under the same steady-state ketamine conditions, the measured impairments in memory performance could not be accounted for by nonspecific effects on attention, general processing, arousal or sedation. While the tasks used to assess declarative memory also demand the use of some additional elements of performance (e.g., sustained attention, working memory), ketamine did not decrease performance on other measures of sustained attention and spatial working memory that were included in the battery. However, psychometric differences in the sensitivity of different tasks could certainly contribute to the apparent "selectivity" of ketamine's effect. In addition, higher doses than those used in this study, or the assessment of performance during the loading and early distribution phase of treatment with the current doses, might yield detectable effects on other cognitive functions. The apparent specificity of ketamine's effect on declarative memory measures at the doses and conditions used in this experiment suggests the hypothesis that brain networks in medial temporal and/or frontal brain regions involved in declarative memory encoding may be preferentially sensitive to functional disruption via blockade of NMDA receptors. The results are consistent with the role of NMDA receptors in the induction of activity-dependent synaptic plasticity and with previous reports of NMDA antagonist effects on memory function in animals and humans.

The cognitive and behavioral effects of ketamine, and the success of an intravenous infusion technique in producing steady-state plasma ketamine concentrations, support the further use of this model for testing the role of NRH in the regulation of schizophrenia-like symptoms in humans. Deficits in declarative memory function represent a prominent and clinically significant feature of schizophrenia (Green 1996). Reductions in the volume of medial temporal lobe structures are associated with memory decreases (Nestor et al. 1993) but specific changes in neural circuitry remain incompletely understood. The current results support the hypothesis that changes in NMDA glutamate receptor activity in one or more neural circuits relevant to declarative memory may be related to impairments found in schizophrenia, suggesting an important focus for future efforts to pharmacologically remediate memory impairments in this disorder.

\section{ACKNOWLEDGMENTS}

Supported by an Independent Scientist Award (MH01510; JWN) from the National Institute of Mental Health (NIMH), MH53363 (JWN), a Scientist Development Award from the National Institute of Drug Abuse (DA00290; NBF), an Established Investigator Award from NARSAD (JWO), a Research Scientist Award from the NIMH (MH38894; JWO), AG11355 (JWO) and U.S.P.H.S. 5M01 RR00036 and P60-DK20579.

\section{REFERENCES}

Aggleton JP, Nicol RM, Huston AE, Fairbairn AF (1988): The performance of amnesic subjects on tests of experimental amnesia in animals: Delayed matching-to-sample and concurrent learning. Neuropsychologia 26(2):265272

Alvarez P, Zola-Morgan S, Squire LR (1994): The animal model of human amnesia: Long-term memory impaired and short-term memory intact. Proc Natl Acad Sci USA 91:5637-5641

Andreasen NC (1982): Negative symptoms in schizophrenia: definition and reliability. Arch Gen Psychiatry 39:784788

Backer-Cave C, Squire LR (1992): Intact verbal and nonverbal short-term memory following damage to the human hippocampus. Hippocampus 2(2):151-164

Bakker CB, Amini FB (1961): Observations on the psychotomimetic effects of Sernyl. Compr Psychiatry 2:269-280

Balster RL, Chait LD (1976): The behavioral pharmacology of phencyclidine. Clin Toxicol 9:513-528

Bliss TVP, Collingridge GL (1993): A synaptic model of memory: Long-term potentiation in the hippocampus. Nature 361(6407):31-39

Buffalo EA, Gillam MP, Allen RR, Paule MG (1994): Acute behavioral effects of MK-801 in rhesus monkeys: Assessment using an operant test battery. Pharmacol Biochem Behav 48(4):935-940

Butelman ER (1989): A novel NMDA antagonist, MK-801, impairs performance in a hippocampal-dependent spatial learning task. Pharmacol Biochem Behav 34:13-16

Butters N, Sax D, Montgomery K, Tarlow S (1978): Comparison of the neuropsychological deficits associated with early and advanced Huntington's disease. Arch Neurol 35:585-589

Cannon TD, Zorrilla LE, Shtasel D, Gur RE, Gur RC, Marco 
EJ, Moberg P, Price RA (1994): Neuropsychological functioning in siblings discordant for schizophrenia and healthy volunteers. Arch Gen Psychiatry 51:651

Clarke RSJ, Bali IM, Issac M, Dundee JW, Sheridan B (1974): Plasma cortisol and blood sugar following minor surgery under intravenous anaesthetics. Anaesthesia 29:545-550

Cohen BD, Rosenbaum G, Luby ED, Gottlieb JS (1962): Comparison of phencyclidine hydrochloride (Sernyl) with other drugs. Arch Gen Psychiatry 6:395-401

Collingridge GL, Bliss TVP (1995): Memories of NMDA receptors and LTP. Trends Neurosci 18(2):54-56

Corssen G, Domino EF (1966): Dissociative anesthesia: Further pharmacologic studies and first clinical experience with the phencyclidine derivative CI-581. Anesth Analg 45:29-40

Craft S, Dagogo-Jack SE, Wiethop BV, Murphy C, Nevins RT, Fleischman S, Rice V, Newcomer JW, Cryer PI (1993): The effects of hyperglycemia on memory and hormone levels in dementia of the Alzheimer type: A longitudinal study. Behav Neurosci 107(6):926-940

Craft S, Newcomer JW, Kanne S, Dagogo-Jack S, Cryer P, Sheline Y, Luby J, Dagogo-Jack A, Alderson A (1996): Memory improvement following induced hyperinsulinemia in Alzheimer's Disease. Neurobiol Aging 17:123-130

Crooks EB, Robinson GS, Hatfield TJ, Graham PW, Gallagher M (1989): Intraventricular administration of the NMDA antagonist APV disrupts learning of an odour aversion that is potentiated by taste. Soc Neurosci Abstr $15: 464$

Danysz W, Wroblewski JT, Costa E (1988): Learning impairment in rats by N-methyl-D-aspartate receptor antagonists. Neuropharmacology 27:653-656

Davies BM, Beech HL (1960): The effect of 1-arylcyclohexylamine (Sernyl) on twelve normal volunteers. J Ment Sci 106:912-924

Davis S, Butcher SP, Morris RGM (1992): The NMDA receptor antagonist D-2-amino-5-phosphonopentanoate (DAP5) impairs spatial learning and LTP in vivo at intracerebral concentrations comparable to those that block LTP in vitro. J Neurosci 12(1):21-34

Deutsch SI, Mastropaolo J, Schwartz BL, Rosse RB, Morihisa JM (1989): A "glutamatergic hypothesis" of schizophrenia. Rationale for pharmacotherapy with glycine. Clin Neuropharmacol 12(1):1-13

Domino E, Luby E (1981): Abnormal mental states induced by phencyclidine as a model of schizophrenia. In Domino E (ed), PCP (Phencyclidine): Historical and Current Perspectives, Ann Arbor, NPP Books, pp 401-418

Doyere V, Laroche S (1992): Linear relationship between the maintenance of hippocampal long-term potentiation and retention of an associative memory. Hippocampus 2(1):39-48

Erard R, Luisada PV, Peele R (1980): The PCP psychosis: Prolonged intoxication or drug-precipitated functional illness? J Psychedelic Drugs 12:235-245

Fahringer EE, Foley EL, Redgate ES (1974): Pituitary adrenal response to ketamine and the inhibition of the response by catecholaminergic blockade. Neuroendocrinology 14:151-164
Farmer R, Pierce C (1974): Plasma cortisol determination: Radioimmunoassay and competitive binding compared. Clin Chem 20:411-414

Frederick DL, Gillam MP, Allen RR, Paule MG (1995): Acute behavioral effects of phencyclidine on rhesus monkey performance in an operant test battery. Pharmacol Biochem Behav 52(4):789-797

Funahashi S, Bruce CJ, Goldman-Rakic PS (1989): Mnemonic coding of visual space in the monkey's dorsolateral prefrontal cortex. J Neurophysiol 61(2):331-349

Gangarosa ME, Saykin AJ, Malamut BL, Gur RC (1988): New scoring systems for the Wechsler Memory Scale: Interrater reliability. J Clin Exp Neuropsychol 10:1-43

Ghoneim MM, Hinrichs JV, Mewaldt SP, Petersen RC (1985): Ketamine: Behavioral effects of subanesthetic doses. J Clin Psychopharmacol 5(2):70-77

Golden CJ (1978): Stroop Color and Word Test: A Manual for Clinical and Experimental Uses. Chicago, Stoelting Co

Goodman Gillman A, Rall TW, Nies AS, Taylor P (1990): The Pharmacological Basis of Therapeutics, 8th ed. New York, Pergamon Press, Inc

Green MF (1996): What are the functional consequences of neurocognitive deficits in schizophrenia? Am J Psychiatry 153:321-330

Gruzelier J, Seymour K, Wilson J (1988): Impairments on neuropsychologic tests of temporohippocampal and frontohippocampal functions and word fluency in remitting schizophrenic and affective disorders. Arch Gen Psychiatry 45:623-629

Handelman GE, Contreras PC, O'Donohue TL (1987): Selective memory impairment by phencyclidine in rats. Eur J Pharmacol 140:69-73

Harris JA, Biersner RJ, Edwards D, Bailey LW (1975): Attention, learning, and personality during ketamine emergence: A pilot study. Anesth Analg 54(2):169-172

Hedlund JL, Vieweg BW (1980): The Brief Psychiatry Rating Scale (BPRS): A comprehensive review. J Oper Psychiatry 11:48-64

Hershey T, Craft S, Glauser TA, Hale S (1998): Short-term and long-term memory in early temporal lobe dysfunction. Neuropsychology 12(1):52-64

Izumi Y, Clifford DB, Zorumski CF (1993): Glucose metabolism and hippocampal long-term potentiation. Soc Neurosci Abstr 19:911

Javitt DC, Zukin SR (1991): Recent advances in the phencyclidine model of schizophrenia. Am J Psychiatry 148(10):1301-1308

Johnstone M, Evans V, Baigel S (1959): Sernyl (CI-395) in clinical anaesthesia. Br J Anaesth 31:433-439

Jones KW, Bauerle L, DeNoble V (1990): Differential effects of sigma and phencyclidine receptor ligands on learning. Eur J Pharmacol 179:97-102

Kaniaris P, Lekakis D, Kykoniatis M, Kastanas E (1975): Serum free fatty acid and blood sugar levels in children under halothane, thiopentone, and ketamine anaesthesia. Can Anaesth Soc J 22:509-518

Kim JS, Kornhuber HH, Holzmuller B, Schmid-Burgk W, Mergner T, Krzepinski G (1980b): Reduction of cerebral spinal fluid glutamic acid in Huntington's chorea and in 
schizophrenic patients. Arch Psychiatry Nervenkr 228: 7-10

Kim JS, Kornhuber HH, Schmid-Burgk W, Holzmuller B (1980a): Low cerebrospinal fluid glutamate in schizophrenic patients and a new hypothesis on schizophrenia. Neurosci Lett 20:379-382

Kowalska DM (1995): Effects of hippocampal lesions on spatial delayed responses in dog. Hippocampus 5:363-370

Krystal JH, Karper LP, Seibyl JP, Freeman GK, Delaney R, Bremner JD, Heninger GR, Bowers MB, Charney DS (1994): Subanesthetic effects of the noncompetitive NMDA antagonist, ketamine, in humans. Arch Gen Psychiatry 51:199-214

Kuzuya H, Blix P, Horwitz D, Steiner D, Rubenstein A (1977): Determination of free and total insulin and C-peptide in insulin-treated diabetics. Diabetes 26:22-29

Lahti AC, Holcomb HH, Medoff DR, Tamminga CA (1995a): Ketamine activates psychosis and alters limbic blood flow in schizophrenia. NeuroReport 6:869-872

Lahti AC, Koffel B, LaPorte D, Tamminga CA (1995b): Subanesthetic doses of ketamine stimulate psychosis in schizophrenia. Neuropsychopharmacology 13(1):9-19

Lodge D, Anis NA (1982): Effects of phencyclidine on excitatory amino acid activation of spinal interneurons in the cat. Eur J Pharmacol 77:203-204

Lodge D, Aram JA, Church J, Davies SN, Martin D, O'Shaughnessy CT, Zeman S (1987): Excitatory amino acids and Phencyclidine-like drugs. In Hicks TP, Lodge D, McLennan H (eds), Excitatory Amino Acid Transmission, New York, Alan R. Liss, Inc, pp 83-90

Luby ED, Cohen BD, Rosenbaum G, Gottlieb JS, Kelley R (1959): Study of a new schizophrenomimetic drug-sernyl. Arch Neuro Psychiatry 81:363-369

Luby ED, Gottlieb JS, Cohen BD, Rosenbaum G, Domino EF (1962): Model psychoses and schizophrenia. Am J Psychiatry 119:61-67

Luciana M, Depue RA, Arbisi P, Leon A (1992): Facilitation of working memory in humans by a D2 dopamine receptor agonist. J Cog Neurosci 4(1):58-68

Malhotra AK, Pinals DA, Adler CM, Elman I, Clifton A, Pickar D, Breier A (1997): Ketamine-induced exacerbation of psychotic symptoms and cognitive impairment in neuroleptic-free schizophrenics. Neuropsychopharmacology 17(3):141-150

Malhotra AK, Pinals DA, Weingartner H, Sirocco K, Missar CD, Picker D, Berier A (1996): NMDA receptor function and human cognition: The effects of ketamine in healthy volunteers. Neuropsychopharmacology 14:301-307

McLamb RL, Williams LR, Nanary KP, Wilson WA, Tilson HA (1990): MK-801 impedes the acquisition of a spatial memory in rats. Pharmacol Biochem Behav 37:41-45

McNamara RK, Skelton RW (1993): The neuropharmacological and neurochemical basis of place learning in the Morris water maze. Brain Res Rev 18:33-49

Milner B (1964): Some effects of frontal lobectomy in man. In Warren JM, Akert K (eds), The Frontal Granular Cortex and Behavior. New York, McGraw-Hill

Mondadori C, Weiskrantz L, Buerki H, Petschke F, Fagg GE (1989): NMDA receptor antagonists can enhance or impair learning performance in animals. Exp Brain Res 75:449-456

Morris RGM (1989): Synaptic plasticity and learning: Selective impairment of learning in rats and blockade of long-term-potentiation in vivo by the N-methyl-D-aspartate receptor antagonist AP5. J Neurosci 9(9):3040-3057

Morris RGM, Anderson E, Lynch GS, Baudry M (1986): Selective impairment of learning and blockade of longterm potentiation by an N-methyl-D-aspartate receptor antagonist, AP5. Nature 319(6056):774-776

Morris RGM, Davis S, Butcher SP (1990): Hippocampal synaptic plasticity and NMDA receptors: A role in information storage? Phil Trans R Soc 329(1253):187-204

Nestor PG, Shenton ME, McCarley RW, Haimson J, Smith RS, O'Donnell B, Kimble M, Kikinis R, Jolesz FA (1993): Neuropsychological correlates of MRI temporal lobe abnormalities in schizophrenia. Am J Psychiatry 150:1849 1855

Newcomer JW, Craft S, Fucetola R, Moldin SO, Paras L, Selke G (1994a): Increase in declarative memory performance during controlled hyperglycemia in patients with schizophrenia. Soc Neurosci Abstr 20(1):810

Newcomer JW, Craft S, Fucetola R, Moldin SO, Selke G, Paras L, Miller R (in press): Glucose-induced increase in memory performance in patients with schizophrenia. Schizophr Bull

Newcomer JW, Craft S, Hershey T, Askins K, Bardgett ME (1994b): Glucocorticoid-induced impairment in declarative memory performance in adult humans. J Neurosci 14(4):2047-2053

Nurnberger JI, Blehar M, Kaufmann CA, York-Cooler C, Simpson S, Harkavy-Friedman J (1994): Diagnostic Interview for Genetic Studies: Rationale, Unique Features, Training. Arch Gen Psychiatry 51:849-859

Oldfield RC (1971): The assessment and analysis of handedness: The Edinburgh Inventory. Neuropsychologia 9:97-113

Olney JW (1988a): Endogenous Excitotoxins and Neuropathological Disorders. In Lodge D (ed), Excitatory Amino Acids in Health and Disease. London, England, John Wiley \& Sons Ltd, pp 337-351

Olney JW (1988b): Excitatory Transmitters and Neuropsychiatric Disorders. In Ferrendelli JA, Collins RC, Johnson EM (eds), Neurobiology of Amino Acids, Peptides, and Trophic Factors. Kluwer Academic Pub, pp 51-61

Olney JW, Farber NB (1995): Glutamate receptor dysfunction and schizophrenia. Arch Gen Psychiatry 52:998-1024

Olney JW, Labruyere J, Price MT (1989): Pathological changes induced in cerebrocortical neurons by phencyclidine and related drugs. Science 244:1360-1362

Overall JE (1974): A brief psychiatric rating scale in psychopharmacology research. In Pichot P (ed), Psychological Measurements in Psychopharmacology, Modern Problems in Pharmacopsychiatry, Vol 7. Basel, Karger, pp $67-78$

Oyama T, Matsumoto F, Kudo T (1970): Effects of ketamine on adrenocortical function in man. Anesth Analg (Cleve) 49:697-700

Pandit KS, Dundee JW, Bovill JG (1971): Clinical studies of 
induction agents XXXVII: Amnesic action of ketamine. Br J Anaesth 43:362-364

Parada-Turska J, Turski WA (1990): Excitatory amino acid antagonists and memory: Effect of drugs acting at $\mathrm{N}$-methyl-D-aspartate receptors in learning and memory tasks. Neuropharmacol 29(2):1111-1116

Pontecorvo MJ, Clissold DB, White MF, Ferkany JW (1991): $\mathrm{N}$-methyl-D-aspartate antagonists and working memory performance: Comparison with the effects of scopolamine, propranolol, diazepam, and phenylisopropyladenosine. Behav Neurosci 105(4):521-535

Rains GD, Milner B (1994): Right-hippocampal contralateralhand effect in the recall of spatial location in the tactual modality. Neuropsychologia 32(10):1233-1242

Reich DL, Silvay G (1989): Ketamine: An update on the first twenty-years of clinical experience. Can J Anaesth 36(2):186-197

Rosenbaum G, Cohen BD, Luby ED, Gottlieb JS, Yelen D (1959): Comparison of Sernyl with other drugs: Simulation of schizophrenic performance with Sernyl, LSD-25, and Amobarbital (Amytal); I. attention, motor function, and proprioception. Arch Gen Psychiatry 1:651-656

Russell EW (1975): A multiple scoring method for assessment of complex memory functions. J Consult Clin Psychol 43:800-809

Sakimura K, Kutsuwada T, Ito I, Manabe T, Takayama C, Kushiya E, Yagi T, Aizawa S, Inoue Y, Sugiyama $\mathrm{H}$, Mishina M (1995): Reduced hippocampal LTP and spatial learning in mice lacking NMDA receptor epsilon 1 subunit. Nature (Lett) 373:151-155

Saykin AJ, Gur RC, Gur RE, Mozley PD, Mozley LH, Resnick SM, Kester DB, Stafiniak P (1991): Neuropsychological function in schizophrenia: Selective impairment in memory and learning. Arch Gen Psychiatry 48:618-624

Saykin AJ, Shtasel DL, Gur RE, Kester DB, Mozley LH, Stafiniak P, Gur RC (1994): Neuropsychological deficits in neuroleptic naive patients with first-episode schizophrenia. Arch Gen Psychiatry 51:124

Shah SD, Clutter WE, Cryer PE (1985): External and internal standards in the single isotope derivative (radioenzymatic) assay of plasma norepinephrine and epinephrine in normal humans and patients with diabetes mellitus or chronic renal failure. J Lab Clin Med 106:624-629

Sherman AD, Davidson AT, Baruah S, Hegwood TS, Waziri R (1991): Evidence of glutamatergic deficiency in schizophrenia. Neurosci Lett 121:77-80

Sidman M, Stoddard LT, Mohr JP (1968): Some additional quantitative observations of immediate memory in a patient with bilateral hippocampal lesions. Neuropsychologia 6:245-254

Spangler EL, Bresnahan EL, Garofalo P, Muth NJ, Heller B, Ingram DK (1991): NMDA receptor channel antagonism by dizocilpine (MK-801) impairs performance of rats in aversively motivated complex maze tasks. Pharmacol Biochem Behav 40(4):949-958

Squire LR, Zola-Morgan S, Chen KS (1988): Human amnesia and animal models of amnesia: Performance of amnesic patients on tests designed for the monkey. Behav Neurosci 102(2):210-221

Squire LR (1987): Memory and Brain, New York, Oxford University Press

Storandt M, Botwinick J, Danziger WL, Berg L, Hughes CP (1984): Psychometric differentiation of mild senile dementia of the Alzheimer type. Arch Neurol 41:497499

Thompson DM, Moerschbaecher JM (1984): Phencyclidine in combination with d-amphetamine: differential effects on acquisition and performance of response chains in monkeys. Pharmacol Biochem Behav 20:619-627

Thompson DM, Winsauer PJ, Mastropaolo J (1987): Effects of phencyclidine, ketamine and MDMA on complex operant behavior in monkeys. Pharmacol Biochem Behav 26:401-405

Tonkiss J, Morris RGM, Rawlins JNP (1988): Intra-ventricular infusion of the NMDA antagonist AP5 impairs performance on a non-spatial operant DRL task in the rat. Exp Brain Res 73:181-188

Tsai G, Passani LA, Slusher BS, Carter R, Baer L, Kleinman JE, Coyle JT (1995): Abnormal excitatory neurotransmitter metabolism in schizophrenic brains. Arch Gen Psychiatry 52:829-836

Vincent JP, Kartalovski B, Geneste P, Kamenka JM, Lazdunski M (1979): Interaction of phencyclidine ("angel dust") with a specific receptor in rat brain membranes. Proc Natl Acad Sci USA 76:4678-4682

Walker DL, Gold PE (1991): Effects of the novel NMDA antagonist, NPC 12626, on long-term potentiation, learning and memory. Brain Res 549(2):213-221

Ward L, Mason SE, Abraham WC (1990): Effects of the NMDA antagonists, CPP and MK-801 on the radial arm maze performance in rats. Pharmacol Biochem Behav 35:785-790

Wechsler D (1945): A standardized memory scale for clinical use. J Psychol 19:87-95

Wechsler D (1987): Wechsler Memory Scale-Revised. New York, Harcourt Brace Jovanovich

White PF, Way WL, Trevor AJ (1982): Ketamine-Its pharmacology and therapeutic uses. Anesthesiology 56:119136

Winocur G (1978): Effects of interference on discrimination and learning and recall by rats with hippocampal lesions. Physiol Behav 22:339-345

Yesavage JA, Freeman AM III (1978): Acute phencyclidine (PCP) intoxication: Psychopathology and prognosis. J Clin Psychiatry 44:664-665

Zola-Morgan S, Squire LR (1985): Medial temporal lesions in monkeys impair memory on a variety of tasks sensitive to human amnesia. Behav Neurosci 99:22-34

Zsigmond EK, Domino EF (1990): Clinical pharmacology of ketamine. In EF Domino (ed), Status of Ketamine in Anesthesiology. Ann Arbor, NPP Books, pp 27-76

Zukin RS, Zukin SR (1979): Specific [ $\left.{ }^{3} \mathrm{H}\right]$ phencyclidine binding in rat central nervous system. Proc Natl Acad Sci USA 76:5372-5376 